\title{
PAISAGENS MAIS-DO-QUE-HUMANAS \\ TRANSFRONTEIRIÇAS NO SUL DO BRASIL: \\ O CASO DO LAMI, PORTO ALEGRE
}

\author{
Andréa Osório (ID \\ Universidade Federal Fluminense-INEST \\ Universidade Federal do Espírito Santo-PGCS \\ Flávio Leonel Abreu da Silveira (1)
}

Bárbara Gonçalves

(1D $\triangle$ 


\section{RESUMO}

O presente artigo é uma incursão preliminar da pesquisa em andamento acerca de uma área de proteção ambiental ao Sul de Porto Alegre (RS), a Reserva Biológica do Lami José Lutzenberger (REBIOLJL), situada numa zona de tensão entre espaços rurais e urbanos. O campo foi efetuado em dois períodos curtos por uma das autoras e em período longo pelos demais autores. O objetivo do artigo é pensar as interações entre a fauna doméstica e a silvestre no escopo da REBIOLJL, sobretudo sua zona de amortecimento, a partir da noção de Paisagem, neste caso, permeada por encontros multiespecíficos. Chamamos atenção para questões relativas ao entorno da Unidade de Conservação (UC) e a porosidade de suas fronteiras.

Palavras-chave: Fauna; Unidade de Conservação; Lami; Cidade; Área Rural.

\section{MORE-THAN-HUMAN LANDSCAPES IN THE SOUTH OF BRAZIL: THE CASE OF LAMI, PORTO ALEGRE}

This paper is a preliminary incursion of a work in progress about a protected natural area south of Porto Alegre (RS), the Lami José Lutzenberger Biological Reserve (REBIOLJL). The field was conducted in two different short periods of time by one author and a longer period by the two other authors. The aim of this paper is to think about the interactions between the domestic and the wild fauna in the scope of the REBIOLJL area and its borders from the perspective of a morethan-human landscape.

Keywords: Fauna; Conservation Unit:

\section{PAISAJES MÁS QUE HUMANOS TRANSFRONTERIZOS EN EL SUR DE BRASIL: EL CASO DE LAMI, PORTO ALEGRE}

El presente trabajo es una incursión preliminar de la investigación en curso en un área de protección ambiental al sur de Porto Alegre (RS), la Reserva Biológica Lami José Lutzenberger (REBIOLJL), ubicada en una zona de tensión entre espacios rurales y urbanos. El campo fue realizado en dos cortos periodos por uno de los autores y en un largo periodo por los otros autores. El objetivo del artículo es reflexionar sobre las interacciones entre la fauna doméstica y salvaje en el ámbito de REBIOLJL, especialmente su zona de amortiguamiento, desde la noción de paisaje, en este caso, permeado por encuentros multiespecíficos. Llamamos la atención sobre temas relacionados con el entorno de la Unidad de Conservación (UC) y la porosidad de sus fronteras.

Palabras clave: fauna; Unidad de Conservación; Lami; Ciudad; zona rural. 


\section{INTRODUÇÃo}

Ao Sul de Porto Alegre encontra-se uma área rururbana que abrange o bairro conhecido como Lami. O logradouro está situado à beira do lago Guaíba e apresenta, na configuração de suas paisagens, uma praia de água doce frequentada pela população da Região Metropolitana, formando um cenário bucólico e bastante atrativo que desempenha papel importante no lazer de parcela dos habitantes da capital gaúcha. Não obstante, a areia da praia é também utilizada por diversos animais, dentre eles destacamos os cães, sendo o local, não raro, depósito de seus excrementos, pois vagam com ou sem donos pelos espaços e ruas do bairro, sobretudo o calçadão de sua orla reformada. Mesmo assim, os banhistas se espalham pela pequena praia no verão, usufruindo suas areias e águas. Um caminho mais longo leva a uma segunda praia, cujo percurso é marcado, dessa vez, pelos excrementos de gado bovino que circula das fazendas contíguas. As paisagens litorâneas do Lami são praticadas - e (de)marcadas
- pelas agências animais - escatológicas, inclusive - queiramos vê-los ou não ${ }^{1}$.

Nem só de animais domésticos criados nos quintais, sítios e fazendas do local está representada a fauna do Lami. Nas ruas do bairro, é possível ver uma série de aves nativas, mas o que chama mesmo a atenção quando olhamos para as árvores da região são os bugios-ruivos (Alouatta guariba clamitans). Animal ameaçado de extinção, o primata circula fora das áreas de conservação em busca de alimentos. Pendurados em fios, eles se arriscam pelos quintais povoados de cães, pelas ruas onde os carros trafegam sem muita frequência e pelas linhas de energia elétrica. Longe de estarem contidos na reserva, expandem seus territórios à zona de amortecimento contígua à área, mas, ao contrário do macacos-prego (Sapajus) estudados por Rapchan (2016: 355) em Maringá, Oeste do Paraná, eles não "geram reações de conflito e competição [com humanos]"2. No Lami, geralmente, os bugios permanecem afastados do interior das residências, mais interessados em folhagens e frutos da área

1 Excrementos de bugios-ruivos também podem ser identificados na orla, especialmente no calçadão, junto às figueiras, que são árvores privilegiadas por esses animais e constituem parte relevante da paisagem local. As praias do Lami foram por muito tempo consideradas impróprias ao banho, diante da quantidade de coliformes fecais humanos presentes em suas águas. Paradoxalmente, as excretas animais seriam o signo de certa qualidade ambiental - sem com isso negarmos a possibilidade de transmissão de doenças - na contramão daquelas humanas: a escatologia indicando tensões entre o rural e o urbano nas paisagens, evidenciando tensões entre modos de vida e práticas distintas do lugar. A própria presença de cães abandonados nos espaços do Lami é um signo da intervenção humana pouco prudente no local.

2 No contexto estudado pela autora, os macacos-prego "agarram rapidamente objetos, peças de roupa ou comida e desaparecem rapidamente, são chamados de ladrões ou invasores, em que pese o fato de alguns moradores dos arredores, principalmente os mais antigos, se encantarem com o contato tão próximo com os macacos e mesmo deixarem frutas não colhidas nas mangueiras ou em fruteiras colocadas nas janelas abertas de suas casas térreas” (Rapchan 2016: 355). 
verde do bairro. São animais maiores que os 'pregos' e podemos dizer que, até certo ponto, com um comportamento menos propício a interações com humanos do que aqueles.

A reflexão que desejamos expor aqui volta-se à convivência de diferentes animais, silvestres e domésticos, em um bairro rururbano da/na capital. Parte das paisagens locais, observadas por nós em caminhadas constantes pelo Lami, revela que os animais povoam o cenário e formam um conjunto de contatos interespecíficos (de proximidade variável), colocando problemas maiores ou menores para a conservação das áreas protegidas numa metrópole como Porto Alegre. De acordo com Rapchan (2016):

\footnotetext{
Esses coletivos [de humanos e animais] são, desse modo, observados a partir de uma relação com a paisagem tomando-a não como pano de fundo, mas como elemento constitutivo, essencial e fundante das relações entre humanos e animais. Aliás, indo além, a própria paisagem deve ser considerada como central nas interações entre humanos e macacos-prego dado que o próprio ponto de partida dessa proposição é diluir o enfoque exclusivo sobre o humano no que diz respeito à construção da sociedade e da sociabilidade e distribuí-lo pelo entorno frequentemente esquecido, subtraído ou subvalorizado. Assim, a paisagem não é considerada aqui exclusivamente como um lugar onde se dão as relações sociais, mas como um fator que modula e é modulado a partir dessas relações de modo a não ser coadjuvante, mas protagonista. (Rapchan 2016: 352).
}

A noção de paisagem, pensada por nós a partir de uma conjunção de fatores antrópicos e não antrópicos, é um dos temas centrais deste artigo, sendo relevante porque diz respeito ao território onde ações e agentes se situam em relação, conformando cenários de interagências complexas e ecologicamente diversas nas feições citadinas. Conforme Bender (1996):

É apenas a partir dos anos 1980 que os
antropólogos começaram a reconhecer
a forma pela qual as percepções das
pessoas sobre o seu mundo e seu
engajamento material com ele estão
intimamente ligados e são criativos
da, bem como criados pela paisagem.
Tal abordagem deixa clara a separação
entre "natureza" e "cultura" e o papel
passivo dado à "natureza" por parte
de um "ponto de vista" ocidental bem
específico. [...] A paisagem nunca é
passiva. As pessoas [e, poderíamos
incluir, os animais] se engajam com
ela, retrabalham-na, se apropriam
dela e a contestam. É parte da forma
pela qual identidades são criadas e
disputadas, sejam individuais, de grupo
ou relativas ao Estado-nação. (Bender
1996: 487-8, tradução nossa).

Nesse sentido, o presente artigo está estruturado de modo a apresentar um pequeno histórico do bairro e da Reserva Biológica do Lami José Lutzenberger (REBIOLJL), sua importância e os animais que a habitam, sem necessariamente efetuar um inventário sobre ambos os temas. A seguir, indicamos os problemas que os cães, sobretudo, representam à conservação das espécies ameaçadas e as soluções que foram ou poderiam ser adotadas pela gestão local da REBIOLJL quanto 
ao convívio dos cães com as espécies ameaçadas de extinção. Por fim, efetuamos uma pequena digressão sobre a rururbanidade ${ }^{3}$ do bairro, tendo em vista as interações de algumas espécies nãohumanas, conforme indicado acima, especialmente que muitas delas são caracteristicamente selvagens. Uma dicotomia entre selvagem e doméstico é, portanto, incluída aqui como uma das chaves analíticas possíveis para se pensar o bairro em questão. Como sede de uma Unidade de Conservação municipal, o Lami nos parece um espaço propício a se pensar as possíveis interações e fronteiras entre tais categorias, especialmente a partir das paisagens praticadas por nós, pesquisadores, e pelos não- humanos aos quais voltamos nossa atenção.

A metodologia básica para a presente reflexão veio a partir de um duplo processo. Ao mesmo tempo em que efetuamos uma etnografia a partir da REBIOLJL, observada desde o cotidiano das práticas de seus funcionários, inclusive junto aos guarda-parques em algumas pontuais incursões deles em sua tarefa de monitoramento do interior da REBIOLJL e do Refúgio de Vida Silvestre São Pedro $(\mathrm{REVIS})^{4}$, também pudemos efetuar uma etnografia de rua (Rocha \& Eckert 2003), caminhando diária e sistematicamente pelo entorno residencial da REBIOLJL, conversando com alguns moradores e fotografando os animais que se apresentavam no percurso, algumas vezes apenas parando para observá-los. Segundo Rocha e Eckert (2003):

A técnica da etnografia de rua consiste na exploração dos espaços urbanos a serem investigados através de caminhadas "sem destino fixo" nos seus territórios. A intenção não se limita, portanto, apenas a retornar o olhar do pesquisador para a sua cidade por meios de processos de reinvenção/reencantamento de seus espaços cotidianos, mas capacitá-lo às exigências de rigor nas observações etnográficas ao longo de ações que envolvem deslocamentos constantes no cenário da vida urbana. [...] Tornarse "um" com os ritmos urbanos é perder-se no meio da multidão, se deixar possuir por alguma esquina, fundir-se nos encontros fortuitos, mas é também localizar-se nas conversas rápidas dos habitantes locais, registrar piscadelas descompromissadas dos passantes, rabiscar apressadamente um desenho destas experiências no seu bloco de notas, "bater" algumas fotos, gravar algumas cenas "estando lá”. [...] Uma etnografia de rua propõe ao antropólogo, portanto, o desafio de experienciar a ambiência das cidades como a de uma "morada de ruas" cujos caminhos, ruídos, cheiros e cores a percorrer sugerem, sem cessar, direções e sentidos desenhados pelo próprio movimento dos pedestres e dos carros que nos conduzem a certos lugares, cenários, paisagens, em detrimento de outros. Deslocamentos marcados por uma forma de apropriação dinâmica da vida citadina, mas cuja apreensão pauta-se pela frequência sistemática do etnógrafo a uma rua ou avenida, um bairro ou uma esquina,

3 O bairro é considerado pela Prefeitura Municipal de Porto Alegre como uma zona rururbana da capital gaúcha. Retomaremos a questão mais adiante.

4 A REVIS fica na localidade denominada de Lageado, bairro contíguo ao Lami, e era gerido, na época, por Maria Carmem Bastos, a mesma gestora da REBIOLJL. 
etc. Neste sentido, a etnografia "na" rua consiste no desenvolvimento da observação sistemática de uma rua e/ou das ruas de um bairro e da descrição etnográfica dos cenários, dos personagens que conformam a rotina da rua e bairro, dos imprevistos, das situações de constrangimento, de tensão e conflito, de entrevistas com habitués e moradores, buscando as significações sobre viver o dia-a-dia na cidade. (Rocha \& Eckert 2003: 105-106).

Não sabemos se fomos mais ou menos felizes em aplicar uma etnografia de rua ao Lami, sobretudo na área do calçadão do lago Guaíba e entorno da REBIOLJL, mas essa foi a forma que nos pareceu mais adequada para compreender a ambiência local. Ao invés de seguir os escassos pedestres e as inexistentes multidões, perseguimos seus animais, dentro do possível, conversamos com protetores e moradores, adentramos UCs junto a guardas-parque, vivenciamos minimamente as questões concernentes à gestão ambiental, banhamo-nos no Guaíba junto aos turistas num fim de semana de sol quente. Em todos esses momentos, as espécies que privilegiamos na presente análise se faziam notar, junto a outras que não impunham tantas tensões entre doméstico e selvagem, rural e urbano - sobretudo as aves. Nossa opção por algumas espécies, portanto, se justifica pelo potencial conflito que geram, o que não significa que outras tantas não estejam visivelmente presentes.

\section{A RESERVA BIOLÓGICA DO LAMI E SEU ENTORNO}

Historicamente, o processo de urbanização da cidade de Porto Alegre concentrou-se na região central, localizada no Noroeste do município, onde havia melhor acesso ao porto, expandindo-se até encontrar barreiras geográficas naturais, como os morros graníticos existentes na região. Essa herança facilita o entendimento da distribuição da ocupação populacional e justifica as características de uma extensa faixa rural situada na Zona Sul do município, especialmente aquela fronteiriça ao município de Viamão, onde a existência de grandes áreas preservadas se fazem presentes no contexto metropolitano e que podem ser visualizadas na delimitação das Macrozonas do Plano Diretor de Desenvolvimento Urbano Ambiental (PDDUA). As Zonas Sul e Extremo Sul do município formam a Macrozona 8, denominada "Cidade Rururbana", dentro da qual se encontra a Zona Rural. Essa é definida como região de "grande patrimônio natural, empresas de produção de alimentos e criação de animais, sítios de subsistência ou lazer, misturados a esparsas áreas de habitação popular” (Lei Complementar $n^{\circ} 434 / 99$, revisada pela LC $n^{\circ}$ 646/10, atualizada e compilada pela LC $\mathrm{n}^{\circ}$ 667/11).

O Lami foi reconhecido como um bairro da capital pela Lei $\mathrm{n}^{\circ} 6.893$, de 12 de setembro de 
1991. Oficialmente, a Prefeitura Municipal de Porto Alegre considera como "Lami”, a região que parte da esquina da Estrada Boa Vista com a Avenida do Lami, e dela até o município de Viamão, junto ao arroio Chico Barcellos, que perfaz o limite entre os dois municípios. Do arroio, segue-se até a sua foz, no lago Guaíba, cuja orla compõe, com a Ponta do Cego e a Ponta das Canoas, até o encontro do prolongamento da Estrada Boa Vista com o Guaíba, parte do bairro. Trata-se de uma área de 2.408 ha e população de 4.642 habitantes, 50,43\% mulheres e $49,75 \%$ homens, segundo o Censo de 2010 (Ibge 2010).

De acordo com os levantamentos do Centro de Pesquisas Históricas, a região do Lami foi, pelo menos até a década de 1970 , povoada predominantemente por pescadores artesanais, sendo considerado um bairro bastante isolado, por não possuir vias de ligação com o Centro, o que dificultava a integração entre os moradores locais e o restante da cidade, bem como impossibilitava as práticas de atividades balneárias junto às margens do lago Guaíba. Dois fatores influenciaram a transformação e o desenvolvimento do bairro: o primeiro foi a construção da estrada de asfalto ligando o Lami ao bairro Belém Novo, possibilitando sua integração econômica e sociocultural com o restante de Porto Alegre; segundo, a constituição, em 1975, da Reserva Biológica do Lami José Lutzenberger (REBIOLJL), considerada a primeira Unidade de Conservação (UC) gerida pelo município de Porto Alegre, diante dos esforços conservacionistas de José Lutzenberger e demais ativistas que atuavam na capital gaúcha à época, o que posteriormente deu nome à área de preservação.

Com o acesso facilitado, a partir de 1992 ocorreram transformações no bairro por meio de um projeto de urbanização e paisagismo, quando recebeu um calçadão, infraestrutura de lazer e novo sistema de iluminação pública constitutivo da orla do Lami, o que paralelamente a liberou para banho, possibilitando que o lugar fosse utilizado como espaço de sociabilidade e evasão pela população gaúcha. O que esse processo indica é que, anteriormente à construção da estrada ${ }^{5}$, o Lami era um bairro relativamente isolado, embora em plena capital gaúcha, com marcas muito características de uma zona ruralizada. Progressivamente e, podemos dizer, recentemente,

5 A estrada tem sido marco recorrente na história brasileira de um processo de expansão da ocupação do solo para regiões antes consideradas escassamente habitadas e, por isso mesmo, de transformação das paisagens associadas à urbanização desenfreada. Por outro lado, o asfalto revela-se elemento marcante nesse processo contínuo de modernização. Corrêa (2011), por exemplo, intitula seu artigo "O mato e o asfalto", numa alusão a um ditado dos anos 1970 que criava fronteiras entre etnólogos indígenas e antropólogos urbanos, o que nos parece, ainda, uma realidade palpável no contexto brasileiro. 
essa aparente ruralidade tem dado espaço a um processo contínuo de urbanização, marcado não apenas pela integração do bairro à cidade por meio de aspectos relacionados à mobilidade, mas também pela ampliação da própria ocupação do solo no Lami, que indica ser a região uma franja da expansão habitacional no contexto portoalegrense.

A região do Lami experimenta, atualmente, um processo de urbanização descontrolado que causa danos à fauna e flora local, pois o bairro, mesmo antes de ser assim definido, já sofria com a ocupação informal por moradores oriundos de outras regiões da capital (ou de municípios gaúchos) e passou a ser alvo também de assentamentos oficiais.

A dissertação de Rechenberg (2007) demonstra como a ocupação do bairro, principalmente após "as obras da Copa" - Copa do Mundo realizada no Brasil em 2014 - fez com que parte da população desalojada nas áreas mais centrais da cidade, se deslocasse para o bairro em busca de terrenos mais baratos para aquisição, ou em certos casos, a fim de ocupar áreas devolutas. Em 2018, por várias vezes, ouvimos de diferentes moradores referências às obras da Copa do Mundo como um dos motivos do "inchaço" do bairro. Isso se reflete diretamente, por exemplo, nas ações humanas sobre os ecossistemas que compõem a região e que impactam de diversas maneiras as espécies animais e vegetais ${ }^{6}$ presentes no local, como é o caso de espécies emblemáticas, como os bugios-ruivos (Alouatta guariba clamitans) e a efédra (Ephedra tweediana), ambas ameaçadas e importantes na tomada de decisão que envolveu a criação da REBIOLJL. Sabe-se que um dos principais motivos para a criação da reserva foi a conservação da efédra, uma planta gimnosperma de distribuição restrita à Lagoa dos Patos, que corre risco de extinção, e que encontra o limite Norte da sua distribuição na cidade de Porto Alegre, mas a distribuição mais austral do primata também contou para a sua efetivação como área de conservação da biodiversidade sulriograndense.

A Reserva, enquanto uma área de conservação urbana, encontra-se numa zona com características rurais e, nesse sentido, poderíamos identificála como rururbana, estando situada no final da microbacia do arroio Lami, que ocupa uma superfície de $39,57 \mathrm{~km}^{2}$ da capital. Sendo assim, a sub-bacia do Lami tem $70 \%$ da sua localização dentro de Porto Alegre e o restante no município vizinho, Viamão. No entanto, a área de influência indireta da REBIOLJL inclui ainda as sub-bacias dos

6 Voltamo-nos principalmente às espécies desses reinos, mas não ignoramos os fungi, por exemplo, como parte do biodiverso naquele contexto. 
arroios Manecão e Chico Barcelos, com superfícies de $19,62 \mathrm{~km}^{2}$ e $9,89 \mathrm{~km}^{2}$, respectivamente (Menegat, Porto \& Carraro 1999). Como área de conservação, a UC é habitat de animais selvagens que, não obstante, podem trafegar pelo seu entorno. Assim, uma tensão emerge entre animais domésticos e selvagens, mas também entre zonas domesticadas (fazendas, haras, quintais, ruas, praia urbanizada, entre outros) e a UC propriamente dita. Entre essas zonas domesticadas, não excluímos, de forma alguma, a estrada de asfalto e os pontos de mais intenso comércio local, onde a (rur)urbanização, entendida como um tipo específico de paisagem, é mais visível.

A região Sul de Porto Alegre detém os últimos remanescentes da Mata Atlântica do município, que se associam a ecossistemas de campos, bem como de restingas, dunas, praias e demais zonas úmidas ${ }^{7}$. Portanto, além da efédra, na área encontram-se espécies ameaçadas da fauna regional, como os bugios-ruivos, a lontra (Lutra longicaudis) e o jacaré-do-papoamarelo (Cayman latirostris), todas oficialmente ameaçadas de extinção, conforme Portaria $\mathrm{n}^{\circ}$ e dos Recursos Naturais Renováveis (IBAMA), além de 115 espécies de aves, incluindo algumas migratórias. Dentre as angiospermas, merecem destaque a corticeira-do-banhado (Erythrina crista-galli), a figueira (Ficus organensis) e a espinheira-santa (Jodina rombipholia).

As paisagens porto-alegrenses naquele trecho delineiam formas impressionantes à vista, indicando não apenas a singularidade ecossistêmica e biodiversa naquele contexto austral brasileiro, mas também uma estética cuja grandiosidade pode ser intuída a partir das palavras do sábio Balduíno Rambo (1994), como segue:

As paisagens mais belas acham-se
do lado oriental, onde o granito, em
toda extensão do Guaíba, termina
abrupto sobre o espelho das águas ou
na sua proximidade. Originam-se assim
numerosas pontas que interrompem
a monotonia da margem com o
ritmo cadenciado de suas formas.
Alternando com praias rasas, ao abrigo
das elevações internas, cercadas de
cintas rochosas sobre a linha de água,
adornadas de belas matas até o topo,
encostadas às pastagens do interior,
produzem um quadro de grande
variedade e beleza. Substituem assim,
embora em escala reduzida, o que a
natureza negou ao litoral marítimo do
Rio Grande do Sul: uma costa rochosa,
convidando o homem a saltar em terra,
a descansar ao abrigo das montanhas
[...]. (Rambo 1994: 96-7).
1.522/89 do Instituto Brasileiro do Meio Ambiente

7 "A reserva situa-se nas terras baixas formadas por terraços lacustres e cordões arenosos que se alternam com zonas mais deprimidas, formando uma variedade de ambientes com diferentes formações vegetais. Nas áreas mais deprimidas e planas, encontram-se banhados, cujo nível de água e extensão variam de acordo com o regime de chuvas e ventos que incidem sobre a Região Hidrográfica do Guaíba. Nas áreas mais elevadas dos cordões arenosos, paralelos à linha da praia, encontram-se campos e matas de restinga. Essas formações mesclam-se com matas ciliares do Arroio Lami e do Lago Guaíba, as quais servem de refúgio, hábitat e corredores de ligação para a fauna" (Menegat, Porto \& Carraro 1999: 89). 


\section{DIMENSÕES SOCIOAMBIENTAIS DA POLÍTICA DE IMPLANTAÇÃO DA REBIOLJL NO CONTEXTO PORTO-ALEGRENSE}

O trabalho de implementação da REBIOLJL iniciou-se efetivamente em 1981, tendo recebido um programa de Educação Ambiental somente a partir de 1992. Na ausência de um Plano de Manejo (PM), o documento Diretrizes de Manejo da Reserva Biológica do Lami (Porto Alegre 1979) foi aplicado até 2002, ano da publicação do primeiro PM oficial. Com a paulatina expansão da área urbana de Porto Alegre em direção à região Sul do município, na qual se localiza a reserva, principalmente a partir da década de 1980, ela passou a ter uma importância estratégica como única Reserva Biológica da capital do Rio Grande do Sul (Printes 2002). Sabese que uma das ferramentas mais importantes do PM é o zoneamento da UC, que a organiza espacialmente em zonas sob diferentes graus de proteção e regras de uso. O PM também inclui medidas para promover a integração da área a ser preservada à vida econômica e social das comunidades vizinhas, o que é essencial para que a implementação da UC seja mais eficiente nos seus objetivos de conservação da biodiversidade. É também neste documento que as regras com relação à visitação são elaboradas e, a partir daí, postas em prática.
Durante o ano de 1999, várias atividades foram desenvolvidas junto à comunidade local com o intuito de aproximá-la da realidade da reserva, visando à realização de um $\mathrm{PM}$ participativo. Em 2000, a situação fundiária foi resolvida com a efetiva ampliação em mais 102,48 ha e a REBIOLJL passou a ter uma área total de 179,78 ha. A partir desse momento, tornou-se mais premente a necessidade de elaboração de um PM participativo, no qual os grandes problemas da reserva, como caça, pesca predatória e loteamentos na zona de amortecimento, pudessem ser debatidos com a comunidade local e de Porto Alegre como um todo.

Foram produzidos dois PMs nesta UC. Em 2002, sob a gestão do biólogo Rodrigo Cambará Printes, foi elaborado o "Plano de Manejo Participativo da Reserva Biológica do Lami”. Em 2008, com a coordenadora à época, Patrícia Bernardes Rodrigues Witt, foi produzido o "Plano de Manejo da Unidade de Conservação Reserva Biológica do Lami José Lutzenberger", ambos aportados conforme o Sistema Nacional de Conservação da Natureza (SNUC), com a promulgação da Lei $\mathrm{n}^{\circ}$ 9.985, de 18 de julho de 2000 , que estabeleceu mecanismos que regulamentam a participação da sociedade na gestão das UC, potencializando a relação entre o Estado, os cidadãos e o meio ambiente. Atualmente, está sendo elaborada uma nova versão do Plano, com previsão de conclusão 
para até o final do ano de 2020, sob a coordenação da atual gestora da UC, a bióloga Maria Carmen Bastos.

É importante lembrar que, pela legislação brasileira, reservas biológicas são UC de proteção integral e devem dispor de um Plano de Manejo elaborado cinco anos após a sua criação, além de um conselho consultivo presidido pelo órgão responsável pela sua administração (Lei Federal $\mathrm{n}^{\circ}$ 9.985, de 18 de julho de 2000). No caso da REBIOLJL, hoje oficialmente localizada em meio rururbano dentro de um bairro de Porto Alegre, torna-se necessário que seu PM seja amplamente discutido com os moradores do entorno e que seu conselho consultivo seja atuante na comunidade. Caso contrário, corre-se o risco de que jamais seja implementado efetivamente. A questão do trânsito de animais silvestres pelas propriedades vizinhas à Reserva é um exemplo de como a UC, para cumprir seus objetivos, depende da colaboração da comunidade lindeira (Printes 2002), aspecto evidenciado pelas nossas observações de campo.

Com relação ao entorno da REBIOLJL, a legislação denomina de zona de amortecimento o que considera como sendo a área localizada dentro de um raio de $10 \mathrm{~km}$ dos limites da UC, conforme a Resolução n ${ }^{\circ}$ 13/90 do Conselho Nacional do Meio Ambiente (CONAMA). Dadas as complexidades existentes ao redor da UC, talvez esse seja um dos maiores desafios para o órgão ambiental gerir a área protegida, pois justamente pelas normas e restrições específicas voltadas à conservação da biodiversidade regional, preconiza-se minimizar os impactos ambientais diretos e indiretos sobre a área de preservação. Essa minimização, contudo, depende não apenas da gestão do que chamaremos aqui de o "interior" da UC que, no caso da REBIOLJL, é uma área amplamente cercada com dispositivos como porteiras, grades e arames farpados (sobretudo, quando as fronteiras se fazem com fazendas). Não apenas os animais domésticos adentram a Reserva, a despeito de seu pretenso cercamento, como animais silvestres trafegam por baixo/ou por orifícios nele, como graxains (Cerdocyon thous) ou saracuras (Aramides cajanea), quanto por cima dele, como pudemos observar em relação aos bugios-ruivos e, é claro, às aves silvestres.

As cercas protegem o local até uma determinada medida, não sendo impeditivos absolutos para o trânsito de espécies humanas e não humanas. Os guardas-parque efetuam, nesse sentido, rondas diárias, noturnas e diurnas, em busca de espécies invasoras (incluindo os humanos) e podem estar associadas, ainda, à verificação da manutenção do local em geral. No entanto, as armadilhas fotográficas dispostas em diversos pontos demonstram que, não obstante, há pontos de 
confluência nos quais transitam animais silvestres e domésticos, embora não seja em qualquer um deles que isso ocorra. As vacas, por exemplo, trafegam na contiguidade das fazendas, ao passo em que os cães circulam por picadas e estradas (nas bordas ou no interior das matas), conforme exploraremos a seguir, da mesma maneira que os bugios-ruivos circulam pela zona contígua à reserva, em pleno bairro, que se tornou uma espécie de área de deambulação para eles, a partir da presença de alguns corredores ecológicos no espaço urbano do logradouro.

É a partir dessas deambulações que nos perguntamos: se animais domésticos adentram a Reserva tanto quando os animais silvestres adentram os quintais, quais são, na prática, os marcos que nos permitiram pensar a urbanização, a ruralidade ou o silvestre no contexto socioambiental do Lami? Incontidos pelas cercas e/ou os dispositivos jurídicos, parece-nos que o bairro comunga de uma dupla ou tripla classificação, o que, naturalmente, leva-nos a pensar qual validade ou valor heurístico essas categorias teriam para uma realidade como a que se apresenta empiricamente no Lami. De antemão, podemos dizer que talvez as fronteiras entre essas categorias sejam borradas pela situação que observamos no bairro. Importante lembrar aqui, por exemplo, que parte da região protegida pela UC foi, no passado, uma fazenda e suas marcas persistem nas paisagens contemporâneas da área de preservação.

No entanto, é bom que se diga que não tomamos a presença dos animais como marcadores isolados. Ao contrário, queremos realçar que a sua presença em meio urbano, rurubano ou rural é, muitas vezes, obliterada pelas pesquisas, quando, na verdade, os animais quase sempre estão lá, de um jeito ou de outro, incluindo-se, é bom que se diga, os silvestres. Trata-se de considerarmos os seus fluxos e as possíveis interagências de que participam nos diferentes contextos pelos quais transitam na urbe, quiçá de seus limites borrados. Trazê-los ao primeiro plano, ao invés de torná-los indícios de ruralidade, urbanização ou de uma paisagem selvagem, é reiterar que eles estão presentes e nos ajudam a pensar essas paisagens tanto quanto nos ajudam a pensar essas categorias e qual a sua validade efetiva para pensarmos as relações simbólico-práticas da conservação.

\section{FAUNA DOMÉSTICA NA ZONA DE AMORTECIMENTO DA REBIOLJL}

O entorno da UC, enquanto um lugar praticado por humanos e não humanos selváticos e domésticos, mas, acima de tudo, no âmbito do bairro; é vivido em termos multiespecíficos, neste caso, mediante situações de proximidade que engendram formas de relações extremamente 
complexas, produzindo "comunidades híbridas" (Lestel 1998), que confundem tais categorias no mundo urbano contemporâneo porto-alegrense. $\mathrm{O}$ encontro entre as diferenças animais em um contexto de heterogeneidade sociocultural, como é o caso dos habitantes do bairro do Lami, sugere a necessidade de reflexões que considerem a presença ativa de coletivos humanos nas tomadas de decisões acerca da conservação do biodiverso junto àquela área de preservação, pela sua importância na manutenção de uma saúde socioambiental na cidade, aliada à manutenção de ecossistemas altamente ameaçados no contemporâneo.

Nesse sentido, as ponderações que realizamos até esta altura do artigo têm dois objetivos fundamentais: 1) apontar a precariedade da preservação ambiental sem a participação da comunidade local e, ao mesmo tempo, 2) indicar a porosidade das fronteiras existentes na vida vivida de humanos e não humanos em relação, a partir do cruzamento de seus lugares praticados e sobre os quais uma UC se assenta, especialmente quando localizada num contexto rururbano de uma metrópole brasileira. A zona de amortecimento da REBIOLJL é composta, sobretudo, por fazendas, sítios e pequenos lotes residenciais que indicam formas distintas de ocupação humana na região, onde a presença de animais domésticos é mais ou menos constante, entre eles o gado bovino e equino ${ }^{8}$ (e mais raramente, ovino), bem como gansos, pombos, coelhos e, principalmente, cães e gatos, o que indica que o manejo de espécies domésticas é comum entre os moradores do bairro, seja como animais de companhia, de consumo ou de tração desde longa data.

As caminhadas pela zona residencial apontaram a predominância de cães em detrimento dos gatos que, não obstante, encontram-se presentes no local. Todavia, a partir de uma razoável observação, percebemos uma constante de três cães por domicílio na zona mais urbanizada, próxima à orla. Além destes animais, que possuem tutores, há uma série de cães e gatos que trafegam nas ruas e avenidas do bairro contíguas à UC. São matilhas, duplas ou, mais raramente, animais solitários que perambulam pelos diversos lugares do bairro, alimentados por seus moradores ou buscando comida no lixo doméstico. Além disso, não raro, alguns dos animais com tutores têm acesso às ruas, como os gatos, por exemplo, ou cães que conseguem transpor as cercas que envolvem a maioria das moradias. Há grupos de gatos que habitam telhados, igualmente alimentados pelos moradores locais, sem com isso serem exatamente domiciliados, mas apresentando-se mais como

8 São muitos os haras na região situados próximos e/ou afastados dos limites da REBIOLJL. 
animais comunitários, como consideraremos esses cães e gatos de rua em geral.

Some-se a isso a observação, bastante comum, da prática de descarte de animais no bairro, situação que pudemos verificar quando, em certa manhã, encontramos uma caixa de papelão com quatro filhotes de cães, que foram acolhidos por moradores da região, sendo que um deles foi levado por alguém, enquanto os demais, posteriormente, devido à nossa intervenção, foram recolhidos por protetores da Grande Porto Alegre. Cavalos também são comuns, normalmente amarrados na vegetação próxima ao calçadão da orla, onde também avistamos, por vezes, vacas, todos pastando no gramado que separa o calçadão das águas do Guaíba, lugar por onde os cães e gatos comumente trafegam. Essa zona de uma pretensa 'natureza' conforma, junto à explícita tentativa de urbanização que a orla representa, a junção dos aspectos que fazem as paisagens do Lami, permeadas por humanos e não humanos em conjunto, todos praticando os mesmos espaços.

Os protetores de animais são uma presença conhecida no bairro. Quando chegamos ao local, logo fomos informados de que havia ao menos duas protetoras residentes, conhecidas pelos demais moradores. Somadas a elas, encontramos uma terceira residindo bem junto a uma das cercas de demarcação da UC, cujo quintal contava sete casinhas de cachorros para cerca de 30 cães e gatos, contabilidade que os funcionários da REBIOLJL não haviam efetuado ainda, mas que os deixou preocupados. Visitamos outra protetora, ainda na zona de amortecimento, residente em um sítio no interior de um condomínio de pequenas propriedades, o que nos parece marcar um novo tipo de ocupação do solo e organização de propriedades rurais, ao mesmo tempo em que indica como a franja de expansão da cidade parece estar se direcionando lentamente para o bairro. A mulher nos informou que haviam 400 cães e 30 gatos, além de galinhas e um cavalo. Em visita à propriedade, a protetora nos contou que havia se mudado para o Lami em busca de espaço para os animais. Não nos parece, é bom que se diga, uma migração do tipo neorrural (Giuliani 1990), pela adoção de um estilo de vida que se poderia considerar tipicamente rural, até porque a propriedade não é produtora, mas eminentemente residencial. Como condomínio fechado, o ambiente ecoa processos típicos da classe média urbana, a que tanto a protetora em questão quanto seu marido pertencem: ele trabalha em um banco fora do Lami e ela gerencia um brechó na Zona Norte da cidade, de onde vem parte da renda que mantém a ação protetiva.

Os funcionários da REBIOLJL, majoritariamente guardas-parque, preocupam-se com a população 
de cães da zona de amortecimento. Quando informamos que havia cerca de 30 animais numa das casas próximas, sua reação foi de consternação, mas quando mencionamos os 400 animais com uma das protetoras, eles se espantaram. Se os cães escapassem, certamente, seria um desastre, todos foram unânimes ${ }^{9}$. O princípio da proteção animal é, justamente, retirar os cães das ruas, portanto, as chances de serem abandonados são mínimas, e as de fugirem são igualmente pequenas. Ainda assim, os funcionários têm razão quanto às suas aflições. As fazendas na zona de amortecimento contam com cães que já foram avistados por eles trafegando dentro da REBIOLJL, bem como as vacas provenientes das fazendas contíguas que, volta e meia, derrubam as cercas de arame farpado, adentrando a reserva.

Quando comparada ao Refúgio de Vida Silvestre São Pedro (REVIS), igualmente gerido por Maria Carmen Bastos, e não muito longe daquela UC, a REBIOLJL detém uma incidência muito menor de cães no seu território, segundo levantamento com armadilhas fotográficas espalhadas em ambas as reservas, mas isso se deve, provavelmente, à inexistência de cercas e presença de estradas de terra na REVIS. Segundo a literatura sobre cães em UCs, é da natureza da espécie trafegar prioritariamente por estradas e picadas, portanto em áreas antropizadas, ao invés de adentrarem zonas de vegetação fechada (Torres \& Prado 2010). Foi justamente nas áreas de estradas que as armadilhas capturaram imagens de cães, acompanhados por humanos ou não, o que demonstra o uso, por esses últimos, da área de conservação para fins desconhecidos.

Destacamos, ainda, que os funcionários realizam constantemente incursões ao interior da UC com o intuito de verificarem, entre outras coisas, a presença canina no território protegido, buscando espantar os animais do seu interior, ou quando possível capturá-los com a intenção de removê-los do local, conduzindo-os aos seus tutores (quando se trata de um animal conhecido), ou encaminhando-os ao canil municipal do Centro de Zoonoses. Foram instaladas, certa vez, armadilhas para a captura de animais, quando um cão oriundo de uma fazenda vizinha foi apreendido e devolvido ao seu tutor, que comprometeu-se de solucionar o problema. Em verdade, passado este episódio, os cães da fazenda novamente foram observados no interior da REBIOLJL.

9 O número de cães na propriedade da protetora em questão é compatível com o espaço disponível, que não seria adequado se os animais fossem de grande porte, como vacas e cavalos. Nesse sentido, é forçoso alertar que um tal contingente de gado bovino ou equino demandaria uma propriedade muito maior e não sabemos se algum dos haras ou fazendas da zona de amortecimento conta com tantos animais, mas é provável que não. 
O que se coloca, ao nosso ver, portanto, é um problema de fronteiras ou, como se diz costumeiramente, os cães - como as vacas - tornamse agenciadores de um "efeito de borda" (Paschoal 2016), de uma tensão e alargamento das fronteiras diante de suas errâncias por espaços de contato entre UC e zona de amortecimento. É conhecido o fato de que a zona de amortecimento é uma faixa porosa onde a contenção dos animais dificilmente consegue ser implementada. Ao trafegarem por ela, nada impede que adentrem a UC. São essas frestas que Douglas (1976) nos ensinou serem ambíguas e poluídas, porque capazes de macularem uma pureza imaginária das UCs, vinculada a certa noção de natureza que despreza a antropia (Diegues 1993).

Ressaltamos que a própria definição de fronteira pode ser obtida na conjunção desses dois fatores: 1) a linha que define um território, no caso, a UC ou sua zona de amortecimento (raio de $10 \mathrm{~km}$ ); 2) "uma área de transição, passagem ou comunicação entre dois estados” (Bolaffi et al. 2003: 123, tradução nossa), tomados os Estados aqui como territórios demarcados sobre terra ou água, e não necessariamente como Estados-nacionais, o que pode ser aplicado, novamente, tanto à UC quanto à sua zona de amortecimento. As fronteiras, portanto, implicam necessariamente algum tipo de fluxo, embora alguns sejam permitidos e outros, interditos, de modo que certas trocas serão vistas como vantajosas, enquanto outras ineficazes e, numa terceira possibilidade, formam 'híbridos' entre elementos de ambos os lados da própria fronteira (Silveira 2005), que parece ser o caso da zona de amortecimento.

Beviláqua (2013), em estudo sobre aspectos jurídicos impostos aos Estados pelas Espécies Exóticas Invasoras ${ }^{10}$ (EEI), identifica um problema de mobilidade que atinge as noções de fronteiras e limites territoriais. Segundo a autora, podemos pensar em: 1) um gradiente entre o tráfego intencional de animais, efetuado dentro das normas constituídas; 2) as migrações, que não necessariamente respeitam fronteiras nacionais e geram uma indeterminação de origem desses animais; e 3) as EEI, mal-acomodadas em tal gradiente, visto que seus deslocamentos se dão "sem periodicidade definida e pode[m] se configurar ao mesmo tempo como legal e ilegal, dependente e independente da ação humana, previsível e imprevisível, ocasional e permanente" (Bevilaqua 2013: 108, grifo original).

Nos casos que analisamos aqui, no que tange ao trânsito de animais silvestres, não se

10 Cães e gatos são considerados espécies exóticas para a fauna brasileira, como todas as espécies domésticas ou silvestres não endêmicas, mas os primeiros podem também ser considerados invasores, quando sua proliferação ameaça a fauna nativa. Uma das autoras deste artigo (Osório, no prelo) trata deste tema separadamente em publicação ainda no prelo. 
trata de migrações, mas de deambulações por um território que ultrapassa a UC, mas que é considerado próprio da espécie ou de grupos (d)e indivíduos em questão. O mesmo é válido para as espécies domésticas, que não respeitam as fronteiras jurídicas instituídas pela UC, cuja legislação não lhes dá cidadania para pertencerem ou trafegarem por seu território protegido, mas que deambulam da mesma forma. Vale lembrar que Leirner (2012) indica que o político é domesticação, no sentido de que o Estado tenta controlar o selvagem e o invasor, mas, no caso das UC, o invasor é o doméstico, invertendo a premissa original do autor, porém mantendo sua lógica. As UC, como espaços estatais, devem controlar seu território e a mobilidade dentro dele, bem como nas fronteiras, mas não podem conter a fauna silvestre que trafega pela zona de amortecimento, como não podem impedir os ataques que ocorrem quando esta fauna adentra quintais com cães e gatos ali confinados. A domesticidade de tais quintais não permite propor nenhum tipo de controle que não seja a própria inexistência dos animais domésticos. Ou seja, mesmo quando os cães e gatos não ultrapassam suas fronteiras domésticas, eles ainda se tornam um problema, visto que os animais silvestres desconhecem essas divisões. O embate territorial destas espécies se dá, portanto, para fora da UC, entendida como um espaço de convívio tensional entre elas, alargando suas fronteiras senão juridicamente, pelo menos na prática.

Se os cães e vacas não podem entrar naquele ambiente, nos parece que outros animais não deveriam sair dele, visão similar a que os habitantes de Maringá estudados por Rapchan (2016) desenvolveram quando os macacos-prego passaram a "invadir'"11, como coloca a autora, entre aspas, espaços vistos como humanos, em oposição às zonas verdes onde eles deveriam permanecer. Esse é o caso dos bugios-ruivos (Alouatta guariba clamitans), por exemplo. Quase que diariamente, por uma zona contígua à REBIOLJL, avistamos inúmeras vezes, grupos pendurados em fios elétricos e árvores. Eles trafegam por telhados, adentram quintais e, muitas vezes, são vítimas dos cães com tutores, restritos ao interior de pátios, como se diz por ali. Suas deambulações são em busca de comida, porém dificultadas pela ausência

11 A noção de uma invasão é simultaneamente típica de um estado bélico que protege fronteiras e das análises sobre espécies exóticas invasoras. O mito de origem do estudo científico das EEI faz referência ao ecologista e biólogo Charles Sutherland Elton (1900-1991), da Universidade de Oxford. Em 1958, ele lançou The Ecology of Invasions by Animals and Plants, obra que abriu caminho para a profusão de publicações que se pode encontrar hoje sobre o assunto (Kitching 2011) e é considerada a mais citada na biologia das invasões (Richardson \& Pyšek 2008). Não foi o primeiro a descrever essas incursões, mas teria fundamentado as bases para um enfoque científico mais sistemático da questão (Richardson \& Pyšek, 2008, Richardson 2011). Simberloff (2011) aponta reiterados usos, por parte de Elton, de "metáforas marciais" para a compreensão de espécies exóticas, metáforas essas que se repetem pelo campo que ele ajudou a fundar e que Simberloff (2011) encontra em autores anteriores, como o próprio Darwin. 
de um corredor propício, quebrado pelos cortes de árvores na zona de amortecimento, realizados por alguns moradores do bairro. Para garantir sua segurança, foram instaladas algumas poucas pontes móveis sobre pontos escolhidos, e que passam por cima de ruas, em percursos onde os bugios normalmente eram avistados. Com nos diz Simmel (1996),

[...] o animal também não deixa de
superar distâncias, e sempre do modo
mais hábil e mais complexo, mas ele
não faz a ligação entre o começo e
o fim do percurso, ele não opera o
milagre do caminho: a saber, coagular
o movimento por uma estrutura sólida,
que parta dele. (Simmel 1996: 11)

A existência de tais pontes configura um conhecimento prático e tácito de que é impossível contê-los dentro da reserva, ao mesmo tempo em que cria um senso de unidade entre suas margens, como salienta Simmel (1996). Há o caso, por exemplo, de uma fêmea de bugio-ruivo que deambulava fora da área da REBIOLJL e que, por falta de árvores (de um corredor ecológico) ou de uma ponte, desceu dela e tentou seguir pelo solo até uma cerejeira-do-mato (Eugenia involucrata) localizada dentro de uma propriedade a fim de comer-lhe os frutos. No entanto, os cães capturaram-na e, diante dos ferimentos sofridos, não resistiu. Sabe-se que outro Alouatta foi morto pelos mesmos cães em circunstâncias parecidas ${ }^{12}$.

Outro animal que (supostamente) trafega é o graxaim-do-mato (Cerdocyon thous), cujo 'primo' graxaim-do-campo também é encontrado na região (Lycalopex gymnocercus). Embora tenham nomes e aspecto parecido, o graxaim-do-campo habita as zonas campeiras úmidas, como seu nome indica, enquanto o graxaim-do-mato prefere bordas de vegetação mais fechada. Ambos são canídeos nativos. Às cinco ou seis da tarde, era costume que um indivíduo se apresentasse na sede da REBIOLJL. Tão comum era sua aparição, que a gestora local começou a desconfiar que algum funcionário do período noturno o estivesse alimentando, o que não excluiria a hipótese de que moradores do entorno fizessem o mesmo. Também era visita constante um lagarto, indivíduo identificado como sendo um teiú-branco (Tupinambis teguixim), que se aproveitava dos restos de refeições presentes na composteira da REBIOLJL, onde era frequentemente avistado.

O ouriço-cacheiro (Sphiggurus villosus) é outra das espécies que os cães com tutores chegaram a atacar durante a pesquisa de campo. Um indivíduo adentrou um pátio e terminou entre os dentes de

12 Além disso, os primatas têm sofrido com a perda de habitats, excesso de parasitismo, atropelamentos e choques elétricos. Apesar desse quadro negativo, o Lami ainda abriga áreas favoráveis aos "macacos urbanos", pois as propriedades de boa parte dos produtores orgânicos do município e últimos pescadores da cidade, além da REBIOLJL e da REVIS, encontram-se na Zona Sul de Porto Alegre. 
um cão. Esse tipo de situação demonstra que os limites da UC são de difícil contenção, tanto em suas entradas quanto em suas saídas. A carcaça de um filhote de capivara (Hydrochoerus hydrochaeris) foi encontrada pela metade, mais recentemente, pelos guardas-parque. Embora esses roedores não costumem sair da REBIOLJL, supõem-se que um cão tenha adentrado a área de banhado onde se concentram. Gatos domésticos também são suspeitos de entrarem, conforme pudemos observar a partir das imagens capturadas pelas armadilhas fotográficas, mas a qualidade noturna da imagem não permite uma certeza sobre a natureza doméstica do animal. Possivelmente, tratava-se de um gato-palheiro (Leopardus colocolo), também conhecido como gato-dos-pampas, felino selvagem típico da região Sul do Brasil.

O elemento comum a todos os ataques é, precisamos reconhecer, antrópico. Não foram necessariamente cães ferais que predaram e devoraram a capivara, morderam o porco-espinho ou mataram indivíduos e espantaram os grupos de bugios-ruivos, mas animais domiciliados ou semidomiciliados. E os ataques parecem se dar muito mais fora da UC, em sua zona de amortecimento, do que dentro dela, o que coloca um problema sobre a porosidade das fronteiras $\mathrm{e}$ o resguardo necessário da fauna selvagem local.

\section{COMO SOLUCIONAR O PROBLEMA?}

A questão acerca do que fazer em relação a tais problemáticas é da alçada de uma "gestão do vivo". E essa foi a pergunta que ouvimos reiteradamente em campo por parte dos funcionários da REBIOLJL diante dos dilemas vividos quanto à conservação das espécies de fauna nativa. Não nos cabia, naquele contexto, respondê-la, na medida em que uma decisão desse porte deve estar amparada pela gestão de conservação e pela legislação vigente, mas uma bibliografia dedicada ao tema aponta certas medidas a serem tomadas.

O problema dos cães e gatos em UCs tem sido trabalhado reiteradamente no conservacionismo nacional (Almeida \& Jesus 2013, Carvalho, Adania \& Esbérard 2013, Galetti \& Sazima 2006, Gatti 2014, Lacerda 2002, Rangel \& Neiva 2013, Sena \& Nascimento 2013, Srbek-Araújo \& Chiarello 2008, entre outros). As soluções normalmente apontadas têm sido alertar a população do entorno das reservas sobre a ameaça que os cães representam à fauna nativa (Carvalho, Adania \& Esbérard 2013), ao mesmo tempo que se solicita restringir sua mobilidade e vaciná-los (SrbekAraújo \& Chiarello 2008). Ziller e Zalba (2007), para os animais domésticos em particular, indicam que não se deve soltá-los na natureza. 
Num estudo na Floresta Nacional de Lorena, São Paulo, Sena e Nascimento (2013) visitaram os quintais das casas no entorno. Encontraram um maior contingente de galinhas e cães, seguidos de gatos e, em menor proporção, passarinhos em gaiolas, jabutis e peixes. De 38 residências, 12 concentravam quase $90 \%$ dos animais. Os autores discutem juridicamente que a presença desses animais não deveria ser permitida no entorno, pois se trata de área de amortecimento, e consideram essencial o controle de mobilidade e a erradicação dos animais em tais contextos.

Galetti e Sazima (2006: 61) sugerem a "erradicação regular de cães e gatos na unidade de conservação" (Reserva Santa Genebra, no estado de São Paulo). Almeida e Jesus (2013) sugerem a conscientização dos donos de gatos quanto à sua mobilidade e abandono, especialmente próximos às florestas, à necessidade de castração, evitar alimentar animais errantes e ferais, e recolhê-los para adoção. As autoras indicam que programas de erradicação são criticados e considerados cruéis na sociedade brasileira. Num estudo comparativo internacional em seis países (Austrália, Nova Zelândia, Reino Unido, Estados Unidos, China e Japão), Hall et al. (2016) indicaram alguns problemas relacionados aos gatos errantes: predação da vida selvagem, transmissão de doenças a humanos, às criações e à vida selvagem, potencial hibridização com gatos selvagens nativos, cruzamento com gatos ferais, incômodo aos vizinhos, por danos a objetos ou espaços e mesmo a animais de estimação. Por último, os autores indicam que a ausência de restrições de mobilidade pode acarretar riscos de morte ao próprio gato. Como solução, os autores indicam a microchipagem do animal, a castração e a restrição da mobilidade, que são sugestões comumente encontradas na literatura e se afinam com prescrições da Organização Mundial da Saúde (World Health Organization 1992) e com aspectos da chamada posse responsável, protocolo de manejo de animais de estimação difundido mundialmente (Osório 2011, 2013).

No caso do Lami, a castração foi organizada junto à Secretaria Municipal do Meio Ambiente e Infraestrutura (SEMA), à Secretaria Especial do Direito dos Animais (SEDA) e à Unidade de Saúde Animal Veterinária (USAV), de forma gratuita. Quando a notícia se espalhou entre os moradores, levou uma parcela significativa da população do bairro a procurar a REBIOLJL em busca de informações e agendamento para seus animais. Isso demonstra que a população tem interesse em ações preventivas, mas tem pouco acesso a elas. Havia datas e vagas preestabelecidas pelo hospital veterinário para a execução das ações e não necessariamente pela demanda que estava surgindo. Dessa forma, as solicitações foram 
organizadas em um cadastro, sendo os moradores chamados de acordo com a disponibilidade de data do (a) tutor(a), assim como pela urgência ou proximidade do animal em relação à UC. Na data acordada, o(a) tutor(a) recebia a equipe da UC para fazer o transporte do animal até o hospital, preenchia uma ficha com informações pessoais e do animal, e por fim assinava um documento se responsabilizando pelos cuidados pós-operatórios. Não havia número limite de castrações por tutor(a).

Consideramos que essa foi uma experiência interessante de ser replicada em outras UC que se encontram em âmbito urbano ou rururbano, na medida em que projetos de castração fazem parte do protocolo da posse responsável, e são um mecanismo considerado eficiente na contenção da reprodução dos animais de estimação. Por outro lado, o abandono de animais no Lami não será necessariamente contido por tais ações, já que podem ser provenientes de outros bairros e regiões de Porto Alegre, o que nos faz considerar que ações de castração deveriam ser contínuas em todas as zonas de baixa renda da cidade, como mecanismo profilático de conservação do ambiente urbano com consequências palpáveis para a zona rural do município.

Se essas ações visam cães e gatos, o mesmo não pode ser implementado com relação aos animais de consumo e tração. Os mecanismos de se lidar com vacas que derrubam cercas e cavalos soltos na orla devem ser de outra natureza, mas em todos os casos uma sensibilização é necessária em relação à comunidade local. Para isso, a REBIOLJL conta com projetos de Educação Ambiental, trilhas guiadas e palestras para grupos escolares ou moradores que queiram conhecer a Reserva. Embora a UC esteja aberta a essa interação, percebemos que muitos moradores da região não sabem sequer onde fica a área de conservação, nem o que ela é ou significa. Tal situação figura como herança de um conservacionismo autoritário de gestão pregressa que afastou as pessoas daquele espaço, limitando o acesso e construindo uma relação de afastamento da comunidade em relação a ele. Nesse sentido, parece-nos que há necessidade de ações mais proativas que envolvam os comunitários nos processos decisórios em torno da conservação da biodiversidade existente na região que, apesar das dificuldades, encontram-se em andamento.

\section{CONSIDERAÇÕES FINAIS}

Tentamos, neste artigo, desenhar um panorama das dinâmicas biossociais que giram em torno da REBIOLJL, na capital gaúcha. O que se evidencia é o caráter fluido das fronteiras de uma UC em espaço rururbano, pois a porosidade reinante que se identifica com derivas não humanas e humanas por elas esboroa, pelo menos parcialmente, a ilusão 
de seletividade que se quer como política efetiva de conservação do vivo, justo porque é imanente no devir agentivo do vivo tensionar fronteiras, ou de realizar agências transfronteiriças. Com isto, não estamos a querer dizer que as fronteiras não possam existir e, mesmo, funcionar no sentido de engendrar certa ordem num aparente caos de errâncias não humanas, especialmente. O que sugerimos é que as fronteiras, os fluxos que as atravessam, neste caso, ou são inerentes ao devir animal nas suas impossibilidades de contenção em territórios específicos, ou são movidos pelos desígnios humanos no seu lugar desestabilizador de fronteiras no mundo, onde as "espécies companheiras" (Haraway 2010) se derivam junto conosco, também se autonomizam nas errâncias que engendram sobre artefatos humanos.

Temos um problema aí que é exatamente aquele da não supressão da liberdade de ir e vir do vivo, que se nos exaspera ou preocupa, por outro lado deveria indicar-nos a relevância dos velhos imponderáveis da vida vivida, que conhecemos de outros contextos etnográficos, mas que, no contemporâneo, para uma Antropologia que se repensa, coloca-nos numa situação de ponderarmos sobre as vicissitudes do vivo com os outros não humanos em contextos de conservação do biodiverso e, assim, nos parece, de instaurarmos novos caminhos de reflexão/interseção que aprofundem os laços rompidos entre cultura e natureza nas sociedades complexas urbano-industriais brasileiras e, consequentemente, em suas paisagens maisdo-que-humanas.

O Lami, como território agentivo de humanos e não humanos, silvestres e domésticos (e, quiçá, liminares, ferais, asselvajados), permite-nos pensar sobre os dilemas da gestão do vivo, sobre as perplexidades quanto às fronteiras de uma UC, bem como sobre as próprias fronteiras entre humanos e animais, quando ambos trafegam pelas mesmas zonas antrópicas. O bairro cheio de bugios-ruivos é silvestre ou doméstico? O bairro rururbano é o local das vacas e cavalos, dos humanos e seu processo produtivo, ou da conservação de espécies em extinção? São os humanos, seus cães, gatos, vacas e cavalos que não deveriam estar ali? Ou são os bugiosruivos, ouriços, graxains e aves que não podem deambular? As respostas não são tranquilas enquanto operarmos por pares de oposição excludentes. Como alerta Simmel (1996: 11), "a noção de separação estaria despojada de sentido se não houvéssemos começado por uni-las, nos nossos pensamentos finalizados, nas nossas necessidades, na nossa imaginação".

De nosso ponto de vista, o Lami é um bairro que congrega todos os agentes supracitados em 
paisagens mais-do-que-humanas. De certo, não é o único no país. Rapchan (2016) indicou como macacos-prego deambulavam por Maringá e é conhecida pela imprensa a deambulação de saguis por bairros do Rio de Janeiro, observada in loco por dois autores deste trabalho. Menos do que descartar agentes, nosso objetivo foi apresentar um panorama para que possamos pensar sobre eles na configuração das paisagens da capital gaúcha e os seus dilemas rururbanos.

\section{REFERÊNCIAS}

Almeida, Sara Miranda e Jesus, Shayana de. 2013. Predação do sabiá-gongá Saltator coerulescens (Thraupidae) e do pardal Passer domesticus (Passeridae) por gato doméstico Felis catus (Carnivora: Felidae). Atualidades Ornitológicas. 175: 18-20.

Bender, B. 1996. Landscape, in Encyclopedia of Social and Cultural Anthropology, editado por Barnard, Alan e Spencer, Jonathan. pp. 487-489. Londres: Routledge.

Bevilaqua, Ciméa. 2013. Espécies invasoras e fronteiras nacionais: uma reflexão sobre os limites do Estado. Revista Anthropológicas. 24 (1):103-123.

Bolaffi, Guido et al. 2003. Frontier in Dictionary of Race, Ethnicity and Culture, pp. 123. Londres: Sage. Brandemburg, Alfio. 2010. Do rural tradicional ao rural socioambiental. Ambiente e Sociedade. 13 (2): 417-428.

Carvalho, W. D.; Adania, C. H. e Esbérard, C. E. L. 2013. Comparison of two mammalian surveys made with camera traps in southeastern Brazil, focusing the abundance of wild mammals and domestic dogs. Brazilian fournal of Biology. 73 (1): 29-36.

Corrêa, Mariza. 2011. O mato e o asfalto: campos da Antropologia no Brasil. Sociologia e Antropologia. 1 (1): 209-229.

De La Cadena, Marisol e Blaser, Mario. 2018. A world of many worlds. Durham: Duke University Press. Diegues, Antônio Carlos Sant`Ana. 1993. Populações Tradicionais em Unidades de Conservação: o mito moderno da natureza intocada. São Paulo: NUPAUB.

Douglas, Mary. 1976. Pureza e perigo. São Paulo: Perspectiva.

Galetti, Mauro e Sazima, Ivan. 2006. Impacto de cães ferais em um fragmento urbano de Floresta Atlântica no Sudeste do Brasil. Natureza \& Conservação. 4 (1): 58-63. 
Gatti, Andressa et al. 2014. Mamíferos de médio e grande porte da Reserva Biológica Augusto Ruschi, Espírito Santo. Natureza on-line. 12 (2): 61-68.

Geertz, C. 1989. A interpretação das culturas. Rio de Janeiro: LTC.

Giuliani, Gian Mario. 1990. Neo-ruralismo: o novo estilo dos velhos modelos. Revista Brasileira de Ciências Sociais. 5 (14): 1-9.

Hall, Catherine M. et al. 2016. Community attitudes and practices of urban residents regarding predation by pet cats on wildlife: an international comparison. PLOS One. http://journals.plos.org/ plosone/article?id=10.1371/journal.pone. 0151962

Haraway, D. 2010. Manifeste des Espèces de Compagnie. Chiens, humains et autres partenaires. Paris: Éditions de l'éclat.

Ibge. 2010. Censo Demográfico. Rio de Janeiro.

Kitching, Roger L. 2011. A world of thought: 'The Ecology of Invasions by Animals and Plants' and Charles Elton's life's work, in Fifty years of invasion ecology: the legacy of Charles Elton, pp. 3-10. Oxford: Blackwell.

Lacerda, Ana Cristyna Reis. 2002. Análise de ocorrência de Canis familiaris no Parque Nacional de Brasília: influência da matriz, monitoramento e controle. Dissertação de mestrado, Instituto de Ciências Biológicas, Universidade de Brasília, Brasília.

Leirner, Piero C. 2012. O Estado como fazenda de domesticação. R@U. 4 (2): 38-70.

Lestel, D. 1998. L'innovation cognitive dans des communautés hybrides homme/animal de partage de sens, d'intérêts et d'affects. Intellectica. 26-27(1-2): 203-226.

Menegat, Rualdo; Porto, M. L. e Carraro, Clóvis Carlos. 1998. Atlas Ambiental de Porto Alegre. Porto Alegre: Editora da Universidade/UFRGS.

Osório, Andréa. 2011. Posse responsável: moral, ciência e educação ambiental em um grupo de protetores de gatos de rua. R@U - Revista de Antropologia Social dos Alunos do PPGAS-UFSCar. 3(2): $51-75$.

Osório, Andréa. 2013. A cidade e os animais: da modernização à posse responsável. Revista Teoria \& Sociedade. 21 (1): 143-176.

Paschoal, Ana Maria Oliveira. 2016. The domestic dog as invasive species in atlantic forest. Tese de doutorado, Instituto de Ciências Biológicas, Universidade Federal de Minas Gerais. 
Porto Alegre. 1979. Diretrizes de manejo da Reserva Biológica do Lami. Porto Alegre: Secretaria Municipal do Meio Ambiente.

Printes, Rodrigo C. 2002. Plano de manejo participativo da Reserva Biológica do Lami. Porto Alegre: SMAM.

Rambo, Balduin. 1994. A Fisionomia do Rio Grande do Sul: ensaio de monografia natural. São Leopoldo: Unisinos.

Rangel, Cristiane Holanda e Neiva, Carla Helena Mendes Buhn. 2013. Predação de vertebrados por cães canis lupus familiaris (Mammalia: Carnivora) no Jardim Botânico do Rio de Janeiro, RJ, Brasil. Biodiversidade Brasileira. 3(2): 261-269.

Rapchan, Eliane Sebeika e Neves, Walter A. 2005a. Chipanzés não amam! Em defesa do significado. Revista de Antropologia. 48(2): 649-98.

Rapchan, Eliane Sebeika. 2005b. Chimpanzés possuem cultura? Questões para a antropologia sobre um tema 'bom para pensar'. Revista de Antropologia. 48(1): 227-280.

Rapchan, Eliane Sebeika. 2016. Casas, espaços públicos e parques: o caso entre os macacos-prego e a cidade em Maringá. Iluminuras. 17 9(42): 350-371.

Rechenberg, Fernanda. 2007. "Vamo falá do nosso Lami": estudo antropológico sobre memória coletiva, cotidiano e meio ambiente no bairro Lami, Porto Alegre. Dissertação de mestrado, Departamento de Antropologia, Universidade Federal do Rio Grande do Sul.

Richardson, David M. e Pyšek, Petr. 2008. Fifty years of invasion ecology - the legacy of Charles Elton. Diversity and Distributions. 14 (2): 161-168.

Richardson, David M. 2011. Introduction, in Fifty years of invasion ecology: the legacy of Charles Elton, pp. 13-19. Oxford: Blackwell.

Rocha, Ana Luiza Carvalho e Eckert, Cornelia. 2003. Etnografia de rua: estudo de Antropologia Urbana. Revista do Núcleo de Desenvolvimento da Criatividade da Unicamp. 9:101-127.

Sena, P. S. e Nascimento, M. M. B. 2013. Conservação e conflito social. Presença de animais domésticos no entorno da Unidade de Conservação: Floresta Nacional de Lorena, Flona Lorena, SP. Âmbito Jurídico. 111. www.ambito-juridico.com.br/site/index.php?n_link=revista_artigos_leitura\&artigo_ id $=13067 \&$ revista_caderno $=5$ 
Silveira, Flávio Leonel Abreu da. 2005. As complexidades da noção de fronteira, algumas reflexões. Caderno Pós Ciências Sociais. 2 9(3): 17-38.

Simberloff, Daniel. 2011. Charles Elton: neither founder nor siren, but prophet, in Fifty years of invasion ecology: the legacy of Charles Elton, pp.11-24. Oxford: Blackwell.

Simmel, Georg. 1996. A ponte e a porta. Revista Política e Trabalho 12(1): 10-14.

Srbek-Araújo, Ana Carolina e Chiarello, Adriano G. 2008. Domestic dogs in Atlantic forest preserves of south-eastern Brazil: a camera-trapping study on patterns of entrance and site occupancy rates. Brazilian fournal of Biology. 68 9(4): 771-779.

Torres, P. C. e Prado, Paulo Inácio. 2010. Domestic dogs in a fragmented landscape in the Brazilian Atlantic Forest: abundance, habitat use and caring by owners. Brazilian fournal of Biology. 70 (4): 987-994.

Veiga, José Eli. 2004. A dimensão rural do Brasil. Estudos Sociedade e Agricultura. 12 (1): 71-94.

World Health Organization. 1992. WHO Expert Commitee on Rabies: eighth report. Geneva: World Health Organization.

Ziller, S. R. e Zalba, S. 2007. Propostas de ação para prevenção e controle de espécies exóticas invasoras. Natureza \& Conservação. 5 9(2): 8-15. 